\title{
Spatial analysis of urban digital divide in Kigali, Rwanda
}

\author{
Chuks Otioma $\cdot$ Ana Mafalda Madureira $₫$ - Javier Martinez
}

Published online: 18 May 2018

(C) The Author(s) 2018

\begin{abstract}
Access to Information and Communications Technologies (ICTs) and its potentials for cities are often uneven across geographies and demographics, a condition that has been referred to as the digital divide. Given the invisibility of digital access, certain geo-demographic groups could face the risk of digital exclusion. However, where not aspatial, most studies explore the digital divide at macro-spatial levels (national and regional levels), which makes them less relevant for knowledge generation and policies at intra-urban scales, the actual hubs of innovations. This paper explores the state of ICT access in Kigali City, at an intra-urban level. It analyses official census data on ICT Access Indicators across dimensions and space, 35 administrative areas called sectors. The paper establishes the relative digital access performance of the sectors based on the measurement of their ICT Location Quotients. In Kigali City spatial distribution of ICT access is significantly clustered, with areas of concentration at the core and sparsity on the northeastern periphery of the city. This espouses spatiality-
\end{abstract}

C. Otioma

United Nations University (UNU-MERIT)/Maastricht

University, Maastricht, The Netherlands

A. M. Madureira $(\bowtie) \cdot$ J. Martinez

Department of Urban and Regional Planning and Geoinformation Management, Faculty of Geo-Information Science and Earth Observation (ITC), University of Twente, Enschede, The Netherlands

e-mail: m.madureira@utwente.nl digitality relations. Using data reduction, we establish that existing urban inequality in infrastructure, urban agglomerative strength, planning status and household socio-economic status are replicated as correlates of the digital divide in Kigali City. We recommend that the baseline spatial-statistical analysis be applied for spatially-targeted ICT policy interventions and that the dimension of ICT be incorporated in policy making targeting urban inequality.

Keywords Urban digital divide - Spatial analysis · ICT cluster $\cdot$ Kigali $\cdot$ Rwanda

\section{Introduction}

Innovations in Information and Communications Technologies (ICTs) have transformed the economic and social formations of cities, and hold promise of enhanced opportunities for citizens (Graham and Marvin 2001). However, disparities exist in the potential access to digital opportunities in terms of availability, use and quality of ICT services among the population. For example, it is estimated that only $34 \%$ of households in developing countries have access to the Internet (UNDP 2015). This kind of disparity has been termed "digital divide", which according to Organisation for Economic Cooperation and Development (OECD)'s (2001) definition (cited in Vicente 
and López 2011) refers to "the gap between individuals, households, businesses and geographic areas at different socio-economic levels with regard to both their opportunities to access ICTs and to use the Internet for a wide variety of activities". A recent literature review of the field of digital divide studies has shown that the concept is often defined as access and use of ICT technologies, invoking as well factors that can influence its use, namely skills, access to technology, education, etc. More recent definitions also focus on digital divide as referring to the social stratification that results from the difference in access, and ability to produce new knowledge in the interaction with ICTs (Hanafizadeh et al. 2013), or what Dodel (2015) refers to as the three stages of hierarchical digital achievements (access, usage and appropriation). Emerging ICT services in urban areas present a mix of opportunities and threat of exclusion of certain segments of the city and can function as an "amplifier of other social and economic factors and processes" (Hanafizadeh et al. 2013: 47). Such exclusion stands a chance of going unnoticed given the invisibility of digital infrastructures (Graham and Marvin 2001).

Following the growing relevance of the digital divide as an element of urban inequality, attempts have been made to account for its factors, often treating socio-economic variables (Eynon and Helsper 2014; Várallyai et al. 2015). Socio-economic strata have been found to be related to the digital divide (Eynon and Helsper 2014): women in Britain have fewer activities online and higher level of education positively correlates with Internet skills and access. Others explore the role of geography, especially distance, centrality and agglomeration, in digital connectivity status and usage (Terlouw and Denkers 2011; Tranos et al. 2014). Graham et al. (2012) have illustrated the profound differences in Internet users that exist between the Global north and the Global south, with countries from the south with very low Internet penetration rates (often lower than $20 \%$ of the population in countries such as Nigeria and Egypt) skewing the geography of Internet access towards Global north (i.e. USA, Canada, most of Western Europe, Australia, Japan, all with over $60 \%$ of Internet penetration).

Although most studies of digital divide have contributed to the general understanding of the phenomenon, research gaps are still identifiable.
Firstly, most of them are only preoccupied with the measurement of digital divide or seek to account for the phenomenon in an abstract space: they are aspatial (for example, van Dijk 2005; van Deursen et al. 2014; van Deursen and Helsper 2015). Secondly, these studies are often conducted at the macro-spatial levels: sometimes at regional scales (Vicente and López 2011), exploring rural-urban divides (Noce and McKeown 2008; Whitacre 2008) and even at country levels, especially those related to Digital Opportunities Index (DOI)/IDI computation (International Telecommunication Union 2014). Pick et al. (2015) posit that apart from the focus on non-spatial multivariate analysis of the digital divide which dominates the literature, those that explore spatial aspects seem to have a paucity of insights into the digital divide at the urban level and are therefore less useful for urban analysis.

A deeper understanding of urban digital divide requires a synthetic approach aimed at benchmarking digital divide at finer spatial scales. In order to address this gap, this paper explores the state of ICT access at an intra-urban level, by assessing the digital performance of Kigali, Rwanda, in terms of physical access to ICTs. It then analyses the relationship between spatial economic factors and digital access performance. By access, we refer to the physical provision of hardware, and aim to map those with access to ICT and those without this access, without distinguishing the equitable and quality aspects linked with individual access to and use of ICTs (Selwyn 2004). We discuss what Selwyn (2004) terms Effective access to ICTthe provision of ICT access at home and within a community, without making any other inferences regarding how the technology is used, what its used for, and how the individual makes use of and interacts with the technology.

The study contributes to the understanding of factors behind digital inequality in divided cities in a spatial context, and as an instrument for micro-level space-based ICT interventions. It provides scope for policies and projects that are aimed at delivering and/ or improving ICT access, especially targeted at the geographic areas and socio-economic groups who are not connected or have poor access to ICTs.

The study of urban digital divide is relevant to African cities for several reasons. In the emergence of cities as an information entity, the cyberspace is fast becoming the new public realm, where those who lack 
the resources to be connected are excluded from the benefits of information technologies (Loader 1998). In a spatial context, in the emergent networked cities the most likely new geographies are such that the premium spaces are connected while the inactive spaces are bypassed (Graham and Marvin 2001). Some corroboration for this proposition is already found in Britain (Riddlesden and Singleton 2014) and South Africa (Jaglin 2008). Additionally, African countries occupy the lowest rungs in ICT Development Index, IDI (International Telecommunication Union, ITU 2017). Within the low performing countries in Africa, in terms of IDI, Rwanda appears somewhere midway, 21 out of 38 countries and 153 out of 176 on a global scale in the ITU ranking.

Rwanda has made remarkable progress in public utilities provision and urbanization policies (Rwanda Utilities Regulatory Authority, RURA 2016). However, it performs low in terms of digital indicators. For example, Rwanda ranks 80 out of 139 countries in the Networked Readiness Index developed by the World Economic Forum, although the index recognizes improvements in the country performance partly due to the national government's focus on a digital agenda and on providing a stable regulatory framework, and the private sector's adoption of digital technologies. It is lagging behind on issues of individual adoption, tied with high prices for broadband and mobile access (World Economic Forum 2016). The Inclusive Internet Access also ranks Rwanda relatively low, due in part to its low performance on issues related with availability and access to local content (63 out of 75 countries), however it ranks high among other lowincome nations, thanks to its infrastructure (The Economist 2017).

Although available indicators such as the ones described above give a country-level view of digital performance, they have less relevance for intra-urban analysis. Therefore, this paper employs a finer spatial scale of analysis of digital access in Kigali in order to determine the pattern of distribution based on selected ICT Access Indicators (AIs) and their relations with spatial-economic variables. ${ }^{1}$ The digital or ICT AIs used here represent physical access (household ownership of ICT assets such as radio, television, mobile

\footnotetext{
${ }^{1}$ Where 'spatial-economic' is used in this paper it comprises the combined geographic, demographic, social and economic factors.
}

phones and computers) and access by location (for example at home, office/school, cyber café).

The paper is structured in the following manner: the literature review discusses the relation between digitality and spatiality, highlighting the role of spatial factors in ICT utilisation. We then contextualize the role of ICT in economic growth promotion and in inclusive city development and explore measurement and conceptual issues in digital divide studies in order to understand how the relationship between digital performance and spatial economic factors has been captured. The third section explains the methodology adopted for this paper, section four describes and discusses the results and the final section draws the main conclusions and contributions of this paper.

\section{ICT and economic growth promotion: between spatiality, digitality and divide}

Spatiality and digitality

In this paper spatiality is used to capture the relation between the spatial distribution of socio-economic activities and the emergence and development of technological clusters, including individual access or otherwise to ICT service. Digitality refers to the pervasive use of mobile telephones, wireless access to information and services on the World Wide Web and the intensified technologically- mediated interactions and cyber-culture among people (Negroponte 1995). According to Thompson (2010) digitality is the instant retrieval of media moments in global consciousness achievable through the computerised encoding of $1 \mathrm{~s}$ and $0 \mathrm{~s}$. These media moments are embedded in global consciousness. More recently, other authors (Scott 2015) argue that there is a diversity of digitalities and that digital practices are related to the context (e.g. political, economic). These views have a common definitional chord: ubiquity of technology-mediated human connectedness beyond agents' physical immediacy (Makela 2001) evidenced by the increasing organisation of social, cultural and political life through global networks (Juris 2012).

Existing spatial structures of resource distribution have influence on whether and to what extent possible users of technology can access the digital space. Studies show that regional agglomerations or where examined at micro-spatial levels, the spatial-economic 
status of any given location is a driver of its share of ICT access and clustering (Graham and Marvin 2001; Crang et al. 2006; Graham 2011; Tranos et al. 2014; Graham 2015; Pick and Nishida 2015). Where interconnectivity of locations within and between cities are explored (for example, Tranos et al. 2014) the distance between any give points determines their probability of being connected.

The possibility of the urban fringe dwellers to be excluded in the emergent spatial structure of the ICTenabled economy is evidence of the instrumentality of space in digital access. This brings our use of the term "Spatiality" closer to that of spatial justice (Soja 2009) and the need to discuss how space both shapes and is shaped by the social (in Soja's words, the sociospatial dialectic). We use "spatiality" to reinforce the notion that geographical uneven development and opportunities can contribute to strengthen pre-existing spatial injustices in the access to opportunities and resources, independently of this unequal access being derived from geographical constraints or inherited from socio-institutional-political structures. In other words, we aim to focus on how this uneven spatial access can rigidify "lasting structures of privilege and advantage" (Soja 2009: 3).

For example, location is shown to play a vital role in not only physical access but also quality of service. Riddlesden and Singleton (2014) found that areas of varying spatial densities experienced fluctuating speed and therefore Quality of Service (QoS) over time. In congruence with this finding, urban peak- off-peak hours and urban mobility behaviour are equally found to drive the daily trends of mobile usage and digital signature of the city, mobile peak- off-peak locations and times (Steenbruggen et al. 2013; Tranos et al. 2013). Kelley (2014) posits that geo-social information tends to be concentrated in the areas of high population density and commercial intensity, albeit with pockets of relatively intense activities in suburban zones. Basu and Chakraborty (2011) found that the existing geo-demographic differentials, which accounted for unevenness in infrastructure access, were replicated in Internet access and speed among farmers across space in the US. Specifically, NonMetropolitan Service Areas in the southern part of the country were found to be dominated by farms with less than $30 \%$ access to high speed Internet.

Fuchs and Horak (2008) analysed the digital divide in Africa, with focus on two cases (Ghana and South
Africa). They found that the Internet access correlates with poverty and Human Development Index (HDI). However, their study was conducted at macro-level, taking countries as the spatial level of analysis. This makes it impossible to observe intra-country and/ intra-regional variations that could be insightful for intra-country patterns and policy interventions. Buys et al. (2009) conducted a spatial-econometric analysis of determinants of the digital divide, based on cell phone (towers) in 41 African countries. They found that spatial factors such as distance to main road, distance to the nearest city, elevation, slope and population are strong determinants of cell phone (tower) diffusion in African countries. While their study, which also considered factors of country competitiveness rating provides some understanding of the macro-level access conditions, it homogenises the digital divide across all cases in Africa. Location of towers does not necessarily mean that possible users near the base stations actually own phones and/or are connected to the Internet. It also numbs certain key demographic and socioeconomic factors that could be important in the digital divide, for example: gender, age and education. Ogutu et al. (2014) found that participants who lived closer to local markets were more likely to participate in technology-based market information services in Kenya.

These conclusions are relevant for the spatialeconomic analysis of ICT access in Kigali because they indicate that by reinforcing existing spatial disparities, differences in ICT access might mean that only the centres might develop into mainstream knowledge based, ICT hubs while the urban peripheries remain weak, less active in ICT. But ICT spread means that the periphery can eventually develop, thereby reaching convergence and well-knit integration of the digital economy. This calls attention to ICT policy interventions and collaborative instruments, which could learn from underlying spatial-economic conditions for specific targeting. Hence, bringing the spatial context to the study of digital divide is of especial importance to research and policy.

Information and communication technologies in economic growth promotion

As urban economies become increasingly information technology-driven it is expected to transform the transactional experience and create a range of 
unprecedented opportunities for users across geographic and socioeconomic strata. In an assessment of digital inclusion projects in 26 selected developing countries, Robin et al. (2017) used key elements such as country commitment, mobile capacity, regulatory environment and adoption and found that the potential for sustainable development of digital finance and financial inclusion are increasingly recognized by the countries in the study. Additionally, they highlighted the potential of financial services and technology to accelerate progress towards financial inclusion, safeguarding that countries commit to facilitate innovation and collaboration between these sectors, and establish regulatory frameworks to guide the progress. In the case of Rwanda, the country is participating in a World Economic Forum project focused on financial inclusion in East Africa, together with Kenya and Tanzania. The project focuses on youth empowerment, gender gap and financing micro, small and medium sized companies through responsible data capturing and data analytics (ITU/UNESCO 2017).

WEF/INSEAD (2016) in Global Information Technology Report (GITR) also recognises Rwanda's efforts to improve ICT development, with the country jumping three places in the ranking (ranking 80 out of 139 countries). The improvement is largely driven by the government efforts to provide a stable regulatory framework and by a private sector that is an eager adopter of digital technologies. Of relevance to our paper is the observation that it is at the level of individual adoption that the country is finding more difficulties in extending its digital agenda, because mobile fees and broadband prices remain high. Henceforth, signalling the heterogeneity of adoption levels and potential digital divide. The GITR report also finds that "digital technologies are unleashing new economic and social dynamics that will need to be managed if the digital transformation of industries and societies are to deliver long-term and broad-based gains" (Baller et al. 2016: xii) which asks governments to be proactive in defining framework conditions for the interaction of these digital technologies and society, in order to secure a long-term and sustainable legacy.

On the promise that ICT holds for urban resilience, a recent study in Costa Rica recognises its role in livelihood and coping capabilities across selected resilience components such as learning, flexibility and diversity (Heeks and Ospina 2018). UN-Habitat officially recognises the role of ICTs in the New
Urban Agenda, incorporated in the proposed post2015 Sustainable Development Goals (SDGs). Modern technology is widely accepted as a way of enabling and measuring the SDGs and is linked with the Open Working Group's Outcome Document in Goal 17 on enhancing the use of enabling technologies and in the report by the Expert Group on Digital Revolution (UN-Habitat 2015, p. 2). This justifies the role of ICTs as urban innovation and inclusive development enablers.

Placing Kigali within the context of urban socioeconomic resilience, ICT (especially household-user access) could enhance value chain in terms of income diversity and redundancy (multiple sources and surplus from safety nets), employment generation (also related to diversity, redundancy and flexibility), information and education, transactional flexibility and rapidity, and multi-actor participation and inclusiveness.

Measuring the digital divide

Several approaches exist which seek to conceptualise, measure and explain digital divide. In their overview of the methodologies used to measure digital divide and e-readiness, Hanafizadeh et al. (2013) identify two broad types of measures. Static measures focus on a set of indicators and make a snap-shot of what is the digital divide at a specific time and place. A second type of measurements looks for the changes in time derived from the evolution of a specific set of indicators. These dynamic types of measurements (Hanafizadeh et al. 2013) offer the possibility to conduct longitudinal studies, however it is often difficult to obtain consistent and reliable data to feed these dynamic measurements.

One example of a static measurement is the Networked Readiness Index (NRI), which conceptualises digital divide using three key dimensions: environment (the ICT market and support services, favourability of regulations and political stability) and stakeholders' readiness to adopt ICT and the actual usage of ICT. However, NRI has been criticised for its cumbersomeness, inconsistency, frequently varying indicators (Pick et al. 2015) and arbitrary assignment of weights to dimensions, which may not reflect local perspectives (Barzilai-Nahon 2006). Nevertheless, it remains one of the most-readily available and global ICT performance references. 
Another well-known framework which employs static measurements is the ITU Guide for Measuring ICT Access 2014 (ITU 2014), which measures the digital divide using three dimensions: opportunities, infrastructure and utilisation. It covers household access by location, use and socio-economic correlates. It is solely applied to national levels, even if its indicators could fit the regions and cities where they are drawn.

This paper adopts the framework of Dewan and Riggins (2005), and applies the ITU indicator-type to explore the digital divide at an intra-urban level in order to understand digital access and urban level determinants. This framework takes into account topical issues (dimensions, indicators and order of access), spatiality (spatial level of analysis, SLA), and theoretical leanings of research and method of analysis. The data used was static. This conceptual framing is justifiable. First there are variants of digital access dimensions and indicators, all of which cannot be covered in a single study. Second, the ITU system of indicators, though frequently reported at country level, is highly adaptable since it is used across countries for ICT access measurement and performance tracking. It has potential for application at intra-regional and intraurban analyses. The focus on first-order and elementary second-order (Internet use by location) is aimed at fitting the study to the context of the stage of ICT development of Kigali. Dewan and Riggins (2005) digital divide research framework is adaptable because it provides a multidisciplinary guide that allows researchers to incorporate elements that are relevant for their field of interest, in this case, our framing of the digital divide analysed at the intra-urban level, applying a spatial econometric method. Any other researcher could have studied the same phenomenon (the digital divide in Kigali, Rwanda) in an aspatial framing and applied a qualitative approach, for instance; or from an orthodox economics perspective, where geography is conceptualised in an abstract sense.

\section{Methodology}

Kigali, a population of 1,132,686 and the capital city of Rwanda, is selected as a case study given its wellarticulated urban development plans, in which ICT has been identified as a cross-cutting and major component, in line with ITU Universal Service Provision/Fund (RURA 2013, 2016). This entails ICT integration with urban planning, health, business and education. However, Kigali is relatively behind in ICT ranking, and internally some of the areas are poor in terms of access and usage, compared to neighbouring countries (ITU 2016). The 35 sectors of Kigali are selected as intra-urban units of analysis. All the 35 sectors are officially classified as "urban".

\section{Data sources}

The digital access data used in this paper is based on ITU ICT access guide (ITU 2014). Key ICT indicators used (for the sector level) are households who own a mobile phone $(\%)$, households with fixed land lines $(\%)$, households with computer $(\%)$, households with Internet at home (\%), households with Internet at work/school (\%), households that use Internet at the cyber café $(\%)$ and household Internet use from other sources, not specified (\%). The source of the digital AIs is the National Institute of Statistics Rwanda (NISR), census released in 2015. The survey covered 286,664 households, with an average size of 3,9 persons/household. Data was only available at the aggregate level of sectors. The access indicators selected and used for digital divide exploration here, fit the stage of ICT development and ICT access-order of the case study researched (Barzilai-Nahon 2006; Dewan and Riggins 2005). Since Kigali is expected to be at the rudimentary stage of digital access the basic indicators of physical access and Internet use are sufficient to explore the pattern of ICT access at this stage.

Socio-economic (SE) data was collected to ascertain the relation between ICT access and SE and spatial variables. SE variables are those that are relevant for ICT access across sectors but which in themselves are not ICT indicators; for example, level of education, household headship (female-headed households), youth population and employment. The data used includes share of total population, urban population, youth population (\%), elderly population (\%), employment by status (\%), employment by type $(\%)$, gender $(\%)$, education by level $(\%)$, female household headship (\%), house ownership (\%), improved water source $(\%)$ and electricity access (\%). Spatial variables are number of innovation centres (schools, at least secondary), natural 
constraints (\% of sector constrained geographically), planning/design status (\%). Geographic constraint is the proportion/percentage of a given sector that is unfavourable for development purposes. Geographic constraint refers to limitations associated with land: unfavourable steepness/topography, soils, wetlands and forests ill-suited for new development based on scientific and ecological principles (City of Kigali 2013). Hence, a sector's share of these physicalecological ills may be indicative of relative backwardness, which could as well be a correlate of performance in emergent technology availability and use. For example difficulty in laying optical fibre, base transceiver stations or poor signal due to geographic constraints could reflect in poor ICT ownership and use in the affected sector. This was used as spatial (economic) indicator.

SE and establishment data (innovation centres/post primary schools) was sourced from NISR, data on geographic constraint was collected from the "City of Kigali Master Plan" (City of Kigali 2013). Age and education components could give insights into the mutual association between cognitive activities (especially education and learning) and ICT access, especially as regards the digital natives (millennials) as strong agents of digitality (Prensky 2001). Gender could help reveal the possible inequality in access to ICTs. Access to physical facilities such as water and electricity could have some relation with ICT indicators, as equally expected of economic geographic/ spatial factors.

\section{Data analysis}

The methodological sequence is organised such as that at the initial stage the relative performances of the subareas (sectors) are presented, using an ICT Location Quotient Aggregate (ICTLQagg). Once this preliminary statistical description is presented, a detailed grouping follows in form of K-means clusters. Though, no causality was sought in the analytical framing of the data, the data reduction method, PCA gives insights into the underlying urban ecological factors (urban socio-economic and spatial conditions associated with the digital divide) of the pattern observed. This part has two sub-steps. First, computing correlation matrix of urban ICT indicators and underlying socio-economic variables for general understanding of interactions. Second, applying PCA as a data reduction technique to determine and select the key factors correlated with ICT conditions in the city. Since we are interested in the patterns and correlates of the digital divide the logical sequence of the method proceeds from observation and description of ICT access and clusters, to the links between ICT access and existing urban ecological conditions of Kigali.

ICT Location Quotient (ICTLQ) was used to determine the performance of the sectors in ICT access. It was computed as the share of ICT for each sector relative to city performance. This is indicative of ICT-orientation and specialisation of each sector. The overall ICT score for each sector, ICT LQ Aggregate (LQICTagg), helped to determine ICTbasic (concentration) and ICT-non-basic (sparsity) sectors. Location Quotient is widely recognised and used in economic geographic analysis to measure the relative performance and concentrations of regional indicators, for example employment shares and technological indicators (Burger et al. 2008; Martin 2012; Smit et al. 2013; US Bureau of Labour Statistics 2011). There are specific applications in Internet geographies in the frame of ICT Location Quotients (Song 2008) and Internet Consumption Quotients (Zook 2001), especially using domain names inventory at macro-spatial levels. While ICT location quotient as applied in this analysis served to summarise the relative concentrations of digital access in Kigali, it lacks the methodological power to show any systematic spatial grouping of the sub-areas hence cluster analysis was employed to detect the various ICT classes, based on their aggregate LQ scores (LQICTagg).

Spatial analysis was conducted using digital access based on output of cluster analysis. Cluster Analysis (CA) was used for spatial grouping of ICT indicators. $\mathrm{K}$-means clustering is widely used in spatial analysis to group observations into similar clusters such that within-group difference is minimised and betweengroup difference is maximised (Rogerson 2015). The CA helped in spatially defining the ICT clusters, and as a tool for determining the influence of the individual indicators on the ICT spatial classification using the ANOVA F-statistics and determining cluster centres. The cluster centres give insights into heterogeneity with groups, showing which administrative sectors are typical representatives of each ICT cluster. GIS software was used to visualise spatial distinctive 
clusters based on the attributes exported from CA output.

Correlation coefficients of digital AIs and spatialeconomic variables were computed to generate a matrix of correlates of the digital divide. This helped to confirm the variables associated with digital access and the understanding of the underlying socio-economic and spatial contexts in which digital performance may be high or low. This does not however seek to investigate and ascribe cause-effect relationships. Given the multiple socio-economic and spatial indicators explored as correlates of the digital divide, Principal Component Analysis (PCA) was applied to reduce the data in order to determine key factors of the distribution. Eigenvalue was set at 1 as cut-off for Principal Components (PCs) selection. The most representative of the dimensions was determined based on Rotated Component Matrix. ${ }^{2}$

The method applied, its appropriateness and statistical power are justifiable on three grounds. First, we followed previous practices in the literature: multivariate research where it has been shown that exploratory data analysis with $\mathrm{N}$ below 50 can yield robust results (De Winter et al. 2009) and clusterbased mapping of the digital divide in the USA with a sample size of 50 administrative units (Pick et al. 2015) and China, 31 administrative units (Pick et al. 2013). Since we assumed no latent causality in the variables of interest the analysis was framed as PCA, not factor analysis, which theoretically differs slightly from the former on the basis of assumption of underlying causal structure. We ensured that the components selected in our analysis were strictly determined by eigenvalue scores greater than 1 (Baum et al. 2004) and in line with De Winter et al. (2009) checked that commonality scores were high (0.8-0.9), to ensure reliability especially since sample size is below 50. The final components in the PCA accounted for $84 \%$ of the total variance observed. Second, the primary focus of the analysis is Kigali, and the data

\footnotetext{
2 The PCA was only applied to spatial grouping of ICT indicators but not to the non-ICT urban socio-economic variables, which are treated as correlates of ICT indicators. The PCA helped unveil the pattern of ICT index only and is based on LQICTagg. PCA, on the other hand, was applied to the non-ICT urban socio-economic variables, which needed to be systematically reduced (not to the ICT indicators). The variables treated with PCA help to understand the urban correlates of digital divide (ICT indicators).
}

analysed covered all sectors that constitute this city. This strengthens its statistical power and internal validity for the case in point, thereby opening opportunities for future research in relevant domains of the digital divide. Third, in line with Baum et al. (2004), our analysis is primarily framed within the context of place-based research and policy hence exploring patterns in ICT access at the level of intra-urban administrative units is sufficient to convey the message "the urban digital divide".

\section{Results and discussion}

Digital access: physical digital asset ownership and use in Kigali

In its individual indicators the sectors of Kigali maintained collectively an excellent performance in terms of mobile phone ownership as shown by $84.8 \%$ mean access score (Table 1). Computer ownership was comparatively low at $13.2 \%$. This pattern of ICT asset ownership is a replica of the observation found in traditional communication assets (radio and TV). While mean percentage access in radio stood at $73.6 \%$, there was a mismatch with TV access score, which stood at relatively low level, $37.7 \%$. Inherently, the issue of cost and socio-economic class could be associated with such a mismatch since these assets of relatively low ownership are more costly than the radio and mobile phone.

The overall pattern of distribution across ICT AIs and space is captured in the ICT Location Quotient (LQICTagg) statistics based on aggregation of sector scores in all AIs relative to Kigali aggregate across all AIs. ${ }^{3}$ The top-performing sectors still remain in the lead in LQICTagg. Beyond single indicator analysis, ICT Location Quotient enables the understanding of the relative concentration of overall digital performance and by extension possible ICT base of the given sectors. LQs are dimensionless (no unit attached, derived from original percentages of ICT indicators) and indicative of ICT-orientation and specialisation of each sector. If the city's performance is 1 , a score above this value by a sector would set the top scoring sector apart from the crowd. Such a sector is

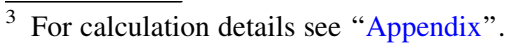


Table 1 ICT AIs of physical access/ownership and use (\%), Kigali, 2012. Data from NISR (2015)

\begin{tabular}{lrr}
\hline AI & Mean & \multicolumn{1}{c}{ SD } \\
\hline Radio & 73.62 & 3.52 \\
TV & 37.71 & 21.68 \\
Fixed telephone & 1.11 & 0.68 \\
Mobile phone & 84.80 & 12.11 \\
Computer & 13.25 & 10.23 \\
Internet (home) & 45.09 & 12.21 \\
Internet (office/school) & 50.61 & 9.52 \\
Internet (cyber café) & 58.09 & 8.73 \\
Internet (others) & 16.86 & 4.53 \\
\hline
\end{tabular}

Original census data is based on 286, 664 households across 35 administrative areas called sectors

designated ICT-Basic (with a strong ICT base and concentration above reference region, Kigali). Such sectors could be designated as achievers (Song 2008) which means in this case they have a strong ICT base and seen as relative premium spaces (Graham and Marvin 2001) in terms of digital access (Fig. 1). ${ }^{4}$

In Kigali, $48.6 \%$ of the 35 sectors are ICT-Basic. The distinctive ICT standing of these sectors is such that the emergent digital culture and economy could be spread from these hubs to the relatively less active spaces or catch up areas, ICT-Non-Basic, with LQICTagg less than or equal to 1 . These are NonBasic because they lack the perquisite urban ICT foundation to be regarded as hubs, where innovation could spread to other sectors. These represent the areas where spread efforts (policy interventions) should be channelled accordingly, to equilibrate any observed spatial divergence in digital access.

Information and communication technology clusters of Kigali

The distinctive ICT clusters of Kigali were mapped using K-means cluster analysis. This helped to group the city into a spatial set of ICT cases with shared characteristics of all the AIs. Table 2 and Fig. 2 summarise the characteristics of the clusters.

\footnotetext{
${ }^{4}$ For details by sector see "Appendix Table 8 ". Sector ICT cluster membership, ICT performance score (LQICTagg) and status.
}

\section{Low non-basic ICT cluster}

This is a suburban cluster made up of mainly the farthest southern and western Kigali with two more sectors on the North- Eastern fringe: the GikomeroRusororo axis. Rusororo embodies the cluster's typical centrality, in terms of ICT characteristics of this cluster. It is the cluster of least ICT access in Kigali. All sectors in the cluster are ICT-Non-Basic (Table 2). It has the least ownership of all physical access and connection/use indicators. It is the most- reliant on Internet café, while it performs least in home connection and use.

\section{High non-basic ICT cluster}

This cluster is mainly non-core Kigali sectors located mostly in the northern region. The cluster fares in the ownership of radio (71.5\%) and mobile phone (72.6\%). However computer ownership is low (2.9\%). Households in the cluster rely more on outside (non-personal) Internet connection (offices/schools and cyber cafés) than home Internet connection. It is made up of the sectors where other access points as mobile Internet buses have a relatively marked presence.

\section{Low basic-ICT cluster}

This is an intermediate and well-performing corecluster of ICT asset ownership and usage. This centrebordering cluster is typified by such sectors as Gatanga and Nyamirambo that are the closest to the central characteristics of this cluster. A shorter distance to the cluster centre (a dimensionless measure) means a stronger exhibition or embodiment of the characteristics of the focus cluster. It maintains a relatively high performance in terms of household ownership of ICT assets (physical access), except fixed telephone, low across all clusters. From Table 2, 91.3\% of the households in the sectors in this cluster own mobile phones, the peak-performing indicator of the cluster. However, mobile phone ownership is not matched with that of computer, which is equally an indicator of modern ICT asset. This is also in contrast to its performance in radio ownership (74.1\%). Offices and schools are the main sources of Internet connection and use. However, this does not detract from the value of mobile phone ownership observed for the cluster, 


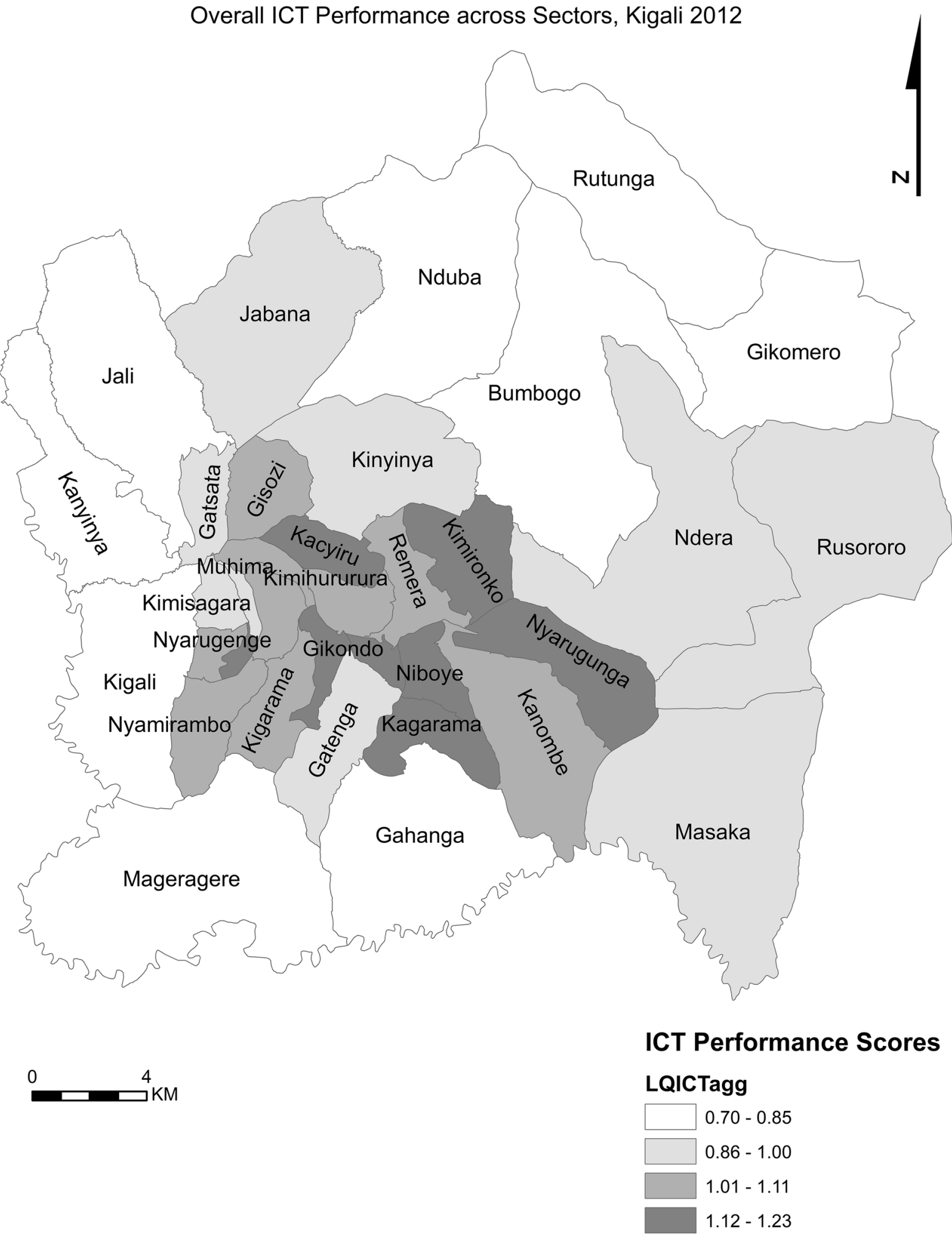

Fig. 1 Overall ICT performance across sectors, measured by LQ of combined AIs, Kigali, 2012. Data from NISR (2015) 
Table 2 Characteristics of ICT clusters (\%) Kigali, 2012. Data from NISR (2015)

\begin{tabular}{lcccc}
\hline AI & Low-non-basic & High non- basic & Low-basic & High-basic \\
\hline Radio & 68.97 & 71.57 & 74.11 & 76.52 \\
TV & 11.00 & 12.37 & 47.87 & 56.64 \\
Fixed telephone & 0.33 & 0.40 & 1.20 & 1.78 \\
Mobile & 68.53 & 72.60 & 91.39 & 94.32 \\
Computer & 1.67 & 2.99 & 12.89 & 24.36 \\
Internet (home) & 29.57 & 39.89 & 44.03 & 55.78 \\
Internet (office/school) & 40.13 & 50.47 & 47.10 & 57.94 \\
Internet (cyber café) & 68.43 & 51.77 & 61.98 & 54.03 \\
Internet (others) & 16.95 & 18.37 & 14.98 & 17.30 \\
\hline
\end{tabular}

since connections such as Wi-Fi and/or modems depend on mobile phones and computers to run.

\section{High basic-ICT cluster}

The core of Kigali maintains the highest level of performance across all indicators of traditional ICT assets and modern connection. Reliance on cyber café and other connection locations is relatively less than either contribution from home or office/school locations. This quality clearly distinguishes it from the other clusters where Internet connection and use in cyber café is still relatively higher than home sources. This contributes to a distinctive character in terms of computer ownership at $24.3 \%$. This cluster is typified by the Kacyiru and Nyarugenge sectors. The high ownership of mobile telephone corresponds to high level connection and use in homes, offices and schools, similar to the Low Basic-ICT cluster. All 13 sectors in this cluster are ICT-basic, while only four in nine are ICT-Basic in the Low Basic-ICT Cluster.

The cluster analysis presented here points to the role of geography in ICT access. The high-performing clusters are geographic cores and economic agglomerations of Kigali in contrast to the peripheral areas that are dominant in all low-performing clusters. However, the distance to cluster centre enables the distinction within clusters. This shows sectors that exhibit more of the distinguishing multiple ICT indicators and characteristics of the focus cluster than others within the same ICT-spatial grouping.
Digital performance and spatial-economic variables

We used a correlation matrix to explore the correlation between spatial-economic variable and digital AIs. ICT assets were treated as a surrogate for socioeconomic material ownership for the purpose of preliminary exploration of the mutual statistical association between any pair of ICT AIs. The two traditional communication assets (radio and TV) were found to strongly correlate, while each showed a statistically strong association with the modern ICT assets, mobile phone and computer ownership. This relationship is stronger between TV and the ownership of these modern ICT assets: mobile phone and computer (Table 3). The observation is understandable as TV symbolises a more recent development (of two traditional assets), expensive and of higher social status. In the acquisition of ICT resources the sectors already atop the existing technologies also possess the newest ICT devices. This is consistent with cumulative causation process (Myrdal 1957) whereby regions with initial socioeconomic advantage continue to dominate in the share of positive development indicators, provided the existing distribution mechanism persists. ICT concentration or Internet users and domain names are a reflection of a city's development towards the digital economy. In this process, positive indicators of digitality will be concentrated in developed regions or urban cores that already possess exceptional socio-economic and spatial development advantage (Zook 2001; Song 2008). Where existing market mechanisms (driven by ICT service providers) target hotspots that are economically better -equipped, digital inequality persists. 

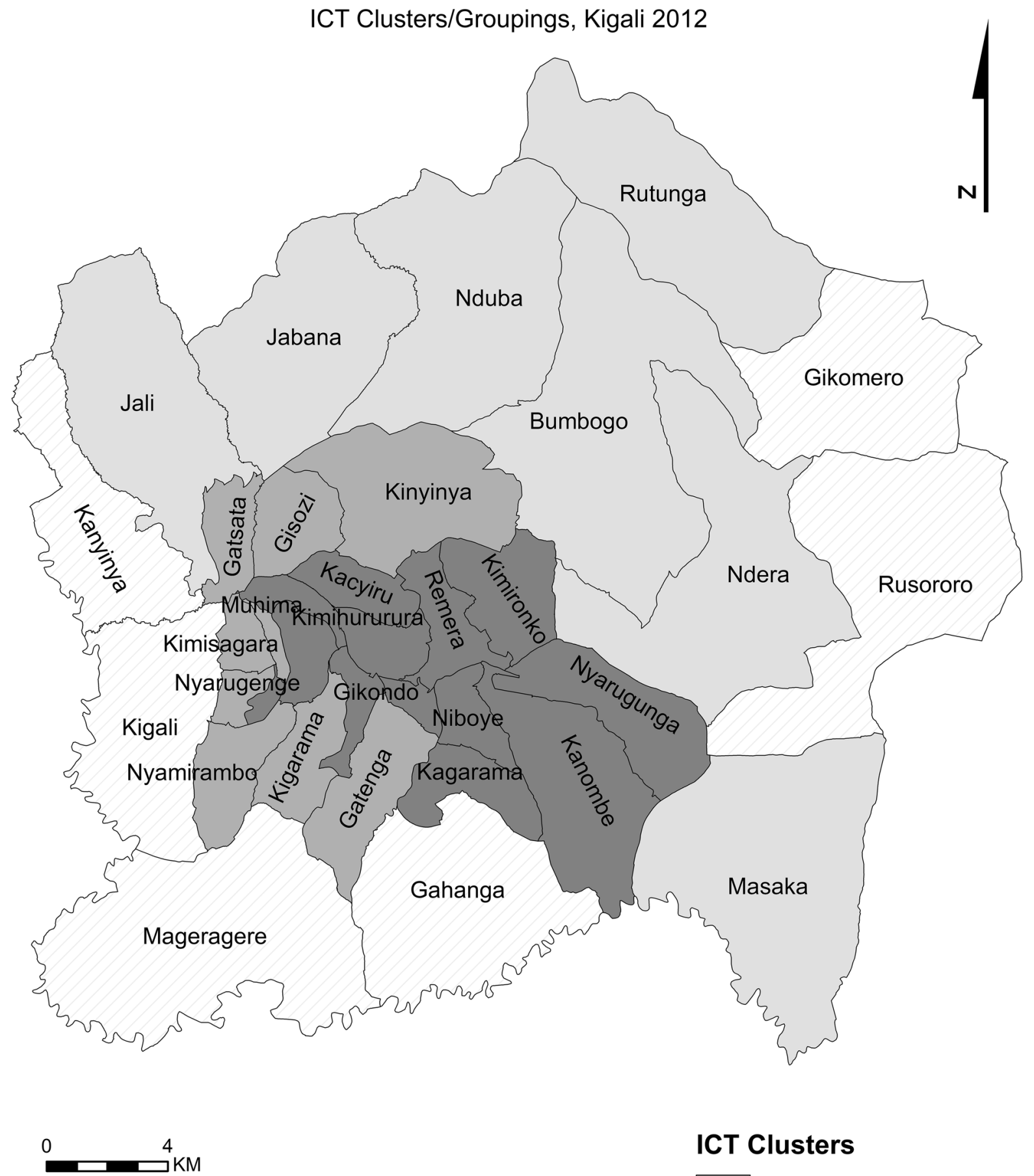

ICT Clusters

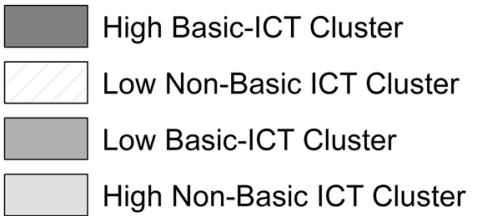

Fig. 2 ICT clusters/groupings of Kigali 2012, based on K-means clusters of AIs. Data derived from NISR (2015) 
Table 3 Mutual relationships between ICT AIs, Kigali, 2012. Data from NISR (2015)

\begin{tabular}{|c|c|c|c|c|c|c|c|c|c|c|}
\hline & $\mathrm{Rad}$ & TV & Fixd & Mobi & Comp & Inthome & Intofsc & Intcafé & Intoth & LQICTagg \\
\hline $\operatorname{Rad}$ & 1 & & & & & & & & & \\
\hline TV & $.813 * *$ & 1 & & & & & & & & \\
\hline Fixd & $.699 * *$ & $.888 * *$ & 1 & & & & & & & \\
\hline Mobi & $.753 * *$ & $.944 * *$ & $.819 * *$ & 1 & & & & & & \\
\hline Comp & $.832 * *$ & $.914 * *$ & $.857 * *$ & $.842 * *$ & 1 & & & & & \\
\hline Inthome & $.580 * *$ & $.681 * *$ & $.671 * *$ & $.633 * *$ & $.777 * *$ & 1 & & & & \\
\hline Intofsc & $.455^{* *}$ & .364 & .347 & $.401 *$ & $.611 * *$ & $.674 * *$ & 1 & & & \\
\hline Intcafé & -.248 & -.091 & -.207 & -.143 & -.257 & $-.519 * *$ & $-.641 * *$ & 1 & & \\
\hline Intoth & .081 & -.099 & -.056 & .024 & .009 & -.001 & .147 & -.292 & 1 & \\
\hline LQICTagg & $.831 * *$ & $.957 * *$ & $.855^{* *}$ & $.929 * *$ & $.965 * *$ & $.796 * *$ & $.575^{* *}$ & -.209 & .033 & 1 \\
\hline
\end{tabular}

*Correlation is significant at 0.05

$* *$ Correlation is significant at 0.01 (2-tailed)

Ownership of mobile phone and computer was found to be associated with Internet use in homes and schools/offices. While not all sector households who own ICT devices might be connected to and use Internet, it is clear that where such connectivity is available, i.e. in offices and schools for instance through $\mathrm{Wi}-\mathrm{Fi}$, it requires these devices to connect and use it. Therefore physical access or ICT material ownership, and Internet connection and use are mutually re-enforcing. Where ownership of ICT assets is high and correlates strongly with Internet connection at home and work locations, cyber cafes become less relevant, as seen in the inverse relationship between the other digital indicators and cyber café usage.

The household status and socioeconomic activity of sectors are associated with ICT indicators (Table 4). Sectors with higher percentage of households headed by females were found to perform less in ICT ownership and use as evidenced by the LQICTagg correlation score corresponding to female household indicator. Such an inverse association between ICT performance and female status also holds for the female population in sector and is statistically strong in terms of overall ICT performance (LQICTagg). This is indicative of a gendered structure of ICT access. Although gender skewness in resource access would ordinary be taken as usual especially in cities in developing countries, this is worth highlighting as recent studies in more developed countries posit that gender is becoming a less relevant correlate of the digital divide ( $\mathrm{Li}$ and Ranieri 2013). Hence, we can argue that at the rudimentary stages of development, gender gap in ICT is stronger, but this tends to weaken as general ICT access improves with narrowing socioeconomic inequalities. However, Li and Ranieri's (2013) study was based on a direct survey and since users' responses sometimes confirm official data or exhibits dissonance, varied narratives could be found if the data used in Kigali was subjected to user survey. Such objective-subjective variances have been found in a study on urban service and quality of life in Ethiopia (Berhe et al. 2014).

Youth population and Education are positively and strongly correlated with ICT performance. These results are in congruence with earlier studies $(\mathrm{Li}$ and Ranieri 2013; Várallyai et al. 2015; Whitacre 2008). Higher percentages of the Youth population and Education mean a larger share of the digital natives (the millennials, born into the digital age).

There is an inverse association between ICT performance and Youth Employment. If conducted at individual levels such relationship could call for concern. However, the relation found in this study means that the sectors with better Internet access coincide with higher unemployment levels. In the context of many African cities, in this case Kigali, the suburban and rural areas typically engage in menial peri-urban farming and other easy-to-start-up informal livelihood support activities that count as 
Table 4 Relationships between ICT access indicators and spatial-economic variables, Kigali, 2012, 2013. Data from NISR (2015)

\begin{tabular}{|c|c|c|c|c|c|c|c|c|c|c|}
\hline Variable & $\operatorname{Rad}$ & TV & Fxd & Mobi & Comp & Inthome & Intofsc & Intcafé & Intoth & LQICTagg \\
\hline Percfemale & -.413 & $-.742 * *$ & $-.775^{* *}$ & $-.737 * *$ & $-.678^{* *}$ & $-.594 * *$ & -.320 & .112 & 139 & $-.719 * *$ \\
\hline Urbanpop & $.659 * *$ & $.918^{* *}$ & $.816^{* *}$ & $.928 * *$ & $.804 * *$ & $.654 * *$ & $.428^{*}$ & -.081 & -.126 & $.900 * *$ \\
\hline Electricity & $.672 * *$ & $.961 * *$ & $.826^{* *}$ & $.953 * *$ & $.828 * *$ & $.658^{* *}$ & .318 & -.032 & -.120 & $.915^{* *}$ \\
\hline Owner & $-.528 * *$ & $-.889 * *$ & $-.777 * *$ & $-.912 * *$ & $-.716^{* *}$ & $-.551 * *$ & -.177 & -.086 & .158 & $-.821 * *$ \\
\hline Elderpop & $-.450 * *$ & $-.753^{* *}$ & $-.591 * *$ & $-.811 * *$ & $-.567 * *$ & $-.491 * *$ & -.227 & -.034 & .174 & $-.706^{* *}$ \\
\hline Elderemployed & $-.445^{*}$ & $-.734 * *$ & $-.554 * *$ & $-.751 * *$ & $-.619 * *$ & $-.580^{* *}$ & -.178 & -.150 & .011 & $-.734 * *$ \\
\hline Youthpop & $.678 * *$ & $.954 * *$ & $.857 * *$ & $.933 * *$ & $.852 * *$ & $.685^{* *}$ & .369 & -.097 & -.081 & $.920 * *$ \\
\hline Youthsec & $.766^{* *}$ & $.954 * *$ & $.889 * *$ & $.925 * *$ & $.834 * *$ & $.625^{* *}$ & .294 & -.087 & -.101 & $.897 * *$ \\
\hline Youthuniv & $.808 * *$ & $.912 * *$ & $.827 * *$ & $.853 * *$ & $.987 * *$ & $.773 * *$ & $.630 * *$ & -.236 & -.037 & $.965 * *$ \\
\hline Youthemployed & -.205 & $-.459 * *$ & $-.450^{* *}$ & $-.468 * *$ & -.406 & $-.479^{* *}$ & -.087 & .020 & -.062 & $-.463^{* *}$ \\
\hline Youthemployee & $.592 * *$ & $.864 * *$ & $.767 * *$ & $.876 * *$ & $.831 * *$ & $.806^{* *}$ & $.492 * *$ & -.201 & -.056 & $.897 * *$ \\
\hline Youthemployer & .252 & $.560 * *$ & $.460 * *$ & $.546 * *$ & $.517 * *$ & $.477 * *$ & .253 & -.108 & -.032 & $.550 * *$ \\
\hline Youthselfemployed & $-.505^{* *}$ & $-.798 * *$ & $-.725^{* *}$ & $-.807 * *$ & $-.768 * *$ & $-.723 * *$ & -.344 & .073 & .076 & $-.817 * *$ \\
\hline Hholdheadfemale & -.255 & $-.494 * *$ & $-.347^{*}$ & $-.533 * *$ & $-.406^{*}$ & $-.466^{* *}$ & $-.348^{*}$ & .038 & .194 & $-.517 * *$ \\
\hline Planned & $.458 * *$ & .375 & .369 & .392 & $.606^{* *}$ & $.519 * *$ & $.645^{* *}$ & -.317 & .130 & $.534 * *$ \\
\hline Improvedwatersource & $.583 * *$ & $.767 * *$ & $.683^{* *}$ & $.782 * *$ & $.712 * *$ & $.457 * *$ & $.357^{*}$ & -.041 & -.025 & $.752 * *$ \\
\hline Geoconstraint & $-.550 * *$ & $-.715^{* *}$ & $-.671 * *$ & $-.672 * *$ & $-.783 * *$ & $-.634^{* *}$ & $-.549 * *$ & .287 & .128 & $-.746 * *$ \\
\hline Postprycentre & .005 & .133 & .209 & .150 & .211 & .261 & .238 & -.006 & -.013 & .211 \\
\hline Sharetotalpop & .132 & .320 & .090 & $.370^{*}$ & .117 & .112 & -.131 & $.359^{*}$ & -.225 & .264 \\
\hline
\end{tabular}

Geographic constraint data was based on CoK (2013)

*Correlation is significant at 0.05

**Correlation is significant at $0.01(2$-tailed)

employment. Highly urbanised areas with more advanced jobs, although having more employed residents, would account for less percentage of the population employed per sector or area. The phenomenon of higher unemployment levels at the city centres could be intensified by the continued attraction of migrants in quest of economic opportunities which are thought to be in abundance at the urban growth centres, thereby further mounting pressure on available opportunities. The problem becomes complicated as most of the new migrants into Sub-Saharan African cities who target city centres are low-skilled and remain unemployed for years (Hove et al. 2013). The core of such cities is characterised by a small enclave of people in high profile jobs, while others are unemployed or unemployable, in an urban labour market being integrated into the fast-paced and technology-based global economy where the education system is not able to meet skills demand (Grant 2012). This is capable of worsening the ratio of the employed to the aggregate population of the core areas, without stripping them of their relative agglomerative and socio-economic advantages, including education, lifestyle, innovation and ICT hubs.

Although Planning Status has a strong positive association with ICT performance across digital indicators, Housing Ownership exhibits another interesting pattern. The highly urbanised sectors, which recorded higher levels of ICT performance, were characterised by higher percentages of tenants and the less urbanised periphery of Kigali was characterised by a higher percentage of home ownership. ${ }^{5}$ This can be explained. A thatched dwelling in the suburban

\footnotetext{
5 Owner in Table 5 (see "Appendix" for a full list of variable names, Table 7).
} 
Table 5 Key components in principal component analysis of spatial-economic variables. Kigali, 2012, 2013. Data from NISR (2015) and CoK (2013)

\begin{tabular}{|c|c|c|c|c|}
\hline \multirow{2}{*}{$\begin{array}{l}\text { Spatial/socio-economic } \\
\text { variables }\end{array}$} & \multicolumn{4}{|c|}{ Component } \\
\hline & 1 & 2 & 3 & 4 \\
\hline Percfemale & -.808 & .234 & .021 & -.047 \\
\hline Sharetotalpop & .137 & -.226 & .881 & -.032 \\
\hline Urbanpop & .871 & -.232 & .271 & .198 \\
\hline Electricity & .911 & -.311 & .223 & .053 \\
\hline Owner & -.850 & .375 & -.272 & -.009 \\
\hline Elderpop & -.788 & .178 & -.439 & .050 \\
\hline Youthpop & .925 & -.312 & .091 & .030 \\
\hline Youthsec & .813 & -.389 & .106 & .128 \\
\hline Youthuniv & .833 & -.232 & -.091 & .350 \\
\hline Youthemployed & -.241 & .908 & -.053 & -.093 \\
\hline Youthemployee & .784 & -.493 & .159 & .268 \\
\hline Youthemployer & .617 & -.110 & .205 & .076 \\
\hline Youthselfemployed & -.672 & .618 & -.164 & -.262 \\
\hline Hholdheadfemale & -.592 & -.137 & -.577 & -.262 \\
\hline Planned & .365 & .024 & -.145 & .775 \\
\hline Improvedwatersource & .761 & .020 & .257 & .262 \\
\hline Geoconstraint & -.755 & .070 & .114 & -.448 \\
\hline Postprycentre & -.114 & -.365 & .341 & .750 \\
\hline Elderemployed & -.572 & .675 & -.338 & -.071 \\
\hline
\end{tabular}

In the rotated component matrix rotation converged in 8 iterations. rotation method: Varimax with Kaiser normalization Extraction method principal component analysis

zone, irrespective of quality (formality or otherwise of housing) is counted as house ownership. Hence, while a high percentage of the comparatively poorer households in peripheral areas of Kigali may own low quality and informal houses, a high percentage of the better educated, higher income and ICT-equipped households would be tenants in well-planned houses. Similar to the unemployed-total population ratio, tenant-ownership ratio is higher at the city core of Kigali where ICT access is higher. This pattern is coherent with NISR (2015) where it was reported that the percentage of house owners are 28.2 and $60.2 \%$ in urban and rural areas respectively, with equivalent tenancy shares of $67 \%$ (urban) and $32.9 \%$ (rural). In the aspect of Urban Agglomeration and Infrastructure correlates of ICT access, sectors' Urban Population Share, Share of Total Population, number of Post Primary Schools (surrogates for innovation centres),
Improved Water Supply and Electricity exhibit positive associations. Electricity (percentage of households with electricity connection in the sectors) and Improved Water Supply have significantly strong correlation with sectors' ICT access, albeit number of Post Primary Schools and Share of Total Population maintain weak associations with ICT performance of sectors (Table 4).

Given the multiple correlates of differential ICT access explored, Principal Component Analysis (PCA) was applied to reduce the data in order to determine key factors of the distribution. Four components were returned as suitable and sufficient representatives of the observed pattern (Table 5). Electricity has the strongest correlation with component 1, Youth Employment with component 2, Share of Total Population with component 3 and Planning Status (proportion of sector planned) component 4. Although the factor grouping performed well, only the most correlated factor with each component was selected as typically representatives (Table 6).

Given this pattern of representative correlation, the socio-economic and spatial variables of ICT access represented were interpretatively inferred to be the following categories: Infrastructure (represented by Electricity), Household structure/socio-economic activity (represented by Youth Employment), Urban agglomerative strength (Share of Total Population) and Planning status/settlement/housing formality (Proportion of Sector Planned). These key factors were primarily used in interpretative context to unveil and confer names to the otherwise statistically anonymous factors (Table 6). Observation of correlations with other variables in Principal Component validates the nomenclature (Pacione 2001).

The general performance of sectors in Kigali as shown in ICT Location Quotients, distinctive spatial grouping of sectors based on ICT performance and correlation exhibit an ICT development pattern in congruence with the classical cumulative causation model (Myrdal 1957). This is the observed pattern in Kigali. Stronger dividing factors (differential socioeconomic characteristics such as spatially uneven electricity, education and planning status) mean that only the centres will develop into mainstream knowledge-based ICT hubs while the peripheries remain weak, less active in ICT. However, ICT spread means increased prospects of the periphery to develop, thereby tending towards convergence and well-knit 
Table 6 Typical/representative variable of spatial-economic correlates of ICT access in Kigali 2012. Data from NISR (2015)

\begin{tabular}{lcccccccccc}
\hline & Rad & TV & Fxd & Mobi & Comp & Inthome & Intofsc & Intcafé & Intoth & LQICTagg \\
\hline Electricity $^{\mathrm{a}}$ & $.672^{* *}$ & $.961^{* *}$ & $.826^{* *}$ & $.953^{* *}$ & $.828^{* *}$ & $.658^{* *}$ & .318 & -.032 & -.120 & $.915^{* *}$ \\
Youthemployed & -.205 & $-.459^{* *}$ & $-.450^{* *}$ & $-.468^{* *}$ & $-.406^{*}$ & $-.479^{* *}$ & -.087 & .020 & -.062 & $-.463^{* *}$ \\
Planned & $.458^{* *}$ & $.375^{*}$ & $.369^{*}$ & $.392^{*}$ & $.606^{* *}$ & $.519^{* *}$ & $.645^{* *}$ & -.317 & .130 & $.534^{* *}$ \\
Sharetotalpop & .132 & .320 & .090 & $.370^{*}$ & .117 & .112 & -.131 & $.359^{*}$ & -.225 & .264 \\
\hline
\end{tabular}

"Youth population correlates strongly with component one but this is somehow replicated in a close variable "youthemployed" in the second component without any competing variable so it would be repetitive to use the youth variable repeatedly. Electricity, next to youth population in correlative strength in component 1 is practicably applied here as an important representative

*Correlation is significant at 0.05

**Correlation is significant at 0.01 (2-tailed)

integration of the digital economy. However, a completely unbundled ICT ecosystem, where providers target only ICT hubs or digital-premium spaces, lacks the perquisite to reduce the digital divide, with all its corollaries of socio-economic and spatial inequalities. Hence, policy intervention becomes critical for stemming divergent factors from turning cumulative effects.

\section{Conclusions}

This paper explored digital divide in Kigali, within the context of spatial and socio-economic correlates of digital access, and possible implications for policy intervention in improving ICT access. In order to establish the existence or otherwise of the digital divide it examined the digital access indicators of ICT asset ownership and use by location. It presented a spatial grouping of indicators, explored relations with correlates across space and tested the spatial pattern of overall access.

The digital divide does exist in Kigali and it is manifested in two ways: ICT access dimensions (assets and use by location) and space, both embedded in existing socio-economic conditions. The study reveals the dominance of household ICT asset ownership of TVs and mobile phones. Internet use by location (home, offices/schools, cyber cafés and others) does not match physical ICT asset ownership. Such a mismatch represents dimensional digital divide. Of all Internet access outlets, cyber café still remains dominant. When this is added to the fact that Internet use is less than household ownership of assets required for Internet it becomes clear that Kigali is at the rudimentary stage of digital access. This is congruent with the assessment made of the country's efforts to improve digital connectivity and access conducted by different organizations (ITU 2017; WEF/INSEAD 2016; The Economist 2017).

On spatial-digital divide, Location Quotient analysis shows administrative sectors with ICT utilisation concentrations, the ICT-Basic sectors, account for $48.6 \%$ of the 35 sectors of Kigali. The spatial grouping of the city into clusters reveals one dominant and high performing cluster at the core of the city, and one intermediate and medium-high performing cluster, composed of a mix of sectors of ICT-Basic and ICTNon-Basic statuses. Two clusters of mainly Non-basic ICT sectors are found in the north- eastern and southwestern peripheries of Kigali. This gives insights into areas that are favourably inclined to ICT and are wellresourced to acquire emerging technologies, with potential for playing a key role in the technologymediated urban services, while others lag behind.

Based on the results it is concluded here that geography and socio-economic conditions do play significant roles in ICT access within a city. Analysis of spatial-economic correlates of ICT access in Kigali indicates that existing conditions that typically underscore the distribution of urban services and opportunities are replicated in ICT access. Additionally, gendering of access is still significant in Kigali and should be taken into consideration for demographic targeting.

The spatial analysis of ICT access in Kigali provides scope for understanding ICT opportunities at the intra-urban levels. Hence, it can aid planners, policy makers, providers and project development partners recognise the need and subsequently integrate ICT dimensions with traditional planning and provision of urban services. Internet access points are a tool 
for digital inclusion and should be incorporated in the design of new public spaces and/or review of existing ones to ensure access across space and groups since the cyber space is fast becoming the new public space. This kind of integration becomes critical when viewed against the background that digital indicators and policy initiatives analysed here confirm that existing infrastructure access and socio-economic strata are correlates of ICT access.

Furthermore, the study contributes to understanding and incorporating emerging dimensions (ICT asset and use) of urban inequality. It contributes to conceptualising unequal access with focus beyond traditional urban infrastructures, services and opportunities. This point is cogent in view of the increasing role of information and cyberspace in modern urban services and daily life, in which old inequalities are being replicated.

We would like to nevertheless acknowledge that digital divide and digital access are influenced by much more that just physical access (Dodel 2015; Selwyn 2004) and therefore this study requires a follow-up into questions of usage, appropriation and outcomes in order to provide policy makers and planners with a more comprehensive understanding of how spatial, social and economic factors can be influencing digital divide at the intra-urban scale.

Acknowledgements The authors would like to thank the insightful and constructive comments of reviewers.

\section{Compliance with ethical standards}

Conflict of interest The authors declare that they have no conflict of interest.

Open Access This article is distributed under the terms of the Creative Commons Attribution 4.0 International License (http:// creativecommons.org/licenses/by/4.0/), which permits unrestricted use, distribution, and reproduction in any medium, provided you give appropriate credit to the original author(s) and the source, provide a link to the Creative Commons license, and indicate if changes were made.

\section{Appendix}

See Tables 7 and 8 .

Table 7 Variables included in the analysis

\begin{tabular}{|c|c|c|c|c|}
\hline Variable label & Full name of variable & Category & Source & Year \\
\hline $\operatorname{Rad}$ & Radio & ICT asset & NISR & 2015 \\
\hline TV & Television & ICT asset & NISR & 2015 \\
\hline Fixd & Fixed telephone & ICT asset & NISR & 2015 \\
\hline Mobi & Mobile phone & ICT asset & NISR & 2015 \\
\hline Comp & Computer & ICT asset & NISR & 2015 \\
\hline Inthome & Internet at home & ICT/Internet use & NISR & 2015 \\
\hline Intofsc & Internet in office/school & ICT/Internet use & NISR & 2015 \\
\hline Intcafé & Internet cyber café & ICT/Internet use & NISR & 2015 \\
\hline Intoth & Internet others & ICT/Internet use & NISR & 2015 \\
\hline Percfemale & Percent of females in the total population & Socio-economic & NISR & 2015 \\
\hline Electricity & Electricity & Socio-economic/infrastructure & NISR & 2015 \\
\hline Owner & Home ownership & Socio-economic & NISR & 2015 \\
\hline Elderpop & Elder population & Socio-economic & NISR & 2015 \\
\hline Youthpop & Youth population & Socio-economic & NISR & 2015 \\
\hline Youthsec & Youth with secondary school education & Social/education & NISR & 2015 \\
\hline Youthuniv & Youth with university education & Social/education & NISR & 2015 \\
\hline Youthemployed & Youth who are employed (status) & Socio-economic & NISR & 2015 \\
\hline Youthemployee & Youth who are employed (type) & Socio-economic & NISR & 2015 \\
\hline Youthemployer & Youth who are employers (type) & Socio-economic & NISR & 2015 \\
\hline Youthselfemployed & Youth who are self-employed (type) & Socio-economic & NISR & 2015 \\
\hline Elderemployed & The Elderly who are employed (status) & Socio-economic & NISR & 2015 \\
\hline
\end{tabular}


Table 7 continued

\begin{tabular}{lllr}
\hline Variable label & Full name of variable & Category & Source \\
\hline Hholdheadfemale & Household headed by female & Socio-economic & NISR \\
Improvedwatersource & Improved source of water & Socio-economic/infrastructure & NISR \\
Planned & Planned habitat & Spatial/formality or informality & NISR \\
Geoconstraint & Geographic constraint & Spatial/agglomerative & City of Kigali \\
Postprycentre & Post-primary education centres & Spatial/agglomerative & NISR \\
Sharetotalpop & Share of total population & Spatial/agglomerative & 2015 \\
Urbanpop & Urban population & Spatial/agglomerative & NISR \\
\hline
\end{tabular}

NISR (2015) is based on National Population Census 2012

Variables in ICT categories are conceptualised to have spatial-economic correlates (the variables in the other categories), treated as the underlying urban condition

Table 8 Sector ICT cluster membership, ICT performance score (LQICTagg) and status

\begin{tabular}{|c|c|c|c|c|c|}
\hline District & Sector & Cluster & Distance to cluster centre & LQICTagg & Status (cluster type) \\
\hline \multirow[t]{15}{*}{ Gasabo } & Bumbogo & 1 & 8.99 & 0.8 & High non-basic ICT \\
\hline & Gatsata & 2 & 10.32 & 0.99 & Low basic-ICT \\
\hline & Gikomero & 3 & 23.87 & 0.7 & Low non-basic ICT \\
\hline & Gisozi & 2 & 19.99 & 1.04 & Low basic-ICT \\
\hline & Jabana & 1 & 16.52 & 0.88 & High non-basic ICT \\
\hline & Jali & 1 & 10.92 & 0.83 & High non-basic ICT \\
\hline & Kacyiru & 4 & 6.15 & 1.12 & High basic-ICT \\
\hline & Kimihururura & 4 & 16.38 & 1.02 & High basic-ICT \\
\hline & Kimironko & 4 & 12.34 & 1.18 & High basic-ICT \\
\hline & Kinyinya & 2 & 23.97 & 0.95 & Low basic-ICT \\
\hline & Ndera & 1 & 11.47 & 0.86 & High non-basic ICT \\
\hline & Nduba & 1 & 16.33 & 0.77 & High non-basic ICT \\
\hline & Remera & 4 & 12.19 & 1.05 & High basic-ICT \\
\hline & Rusororo & 3 & 14.28 & 0.87 & Low non-basic ICT \\
\hline & Rutunga & 1 & 30.08 & 0.77 & High non-basic ICT \\
\hline \multirow[t]{10}{*}{ Kicukiro } & Gahanga & 3 & 14.19 & 0.85 & Low non-basic ICT \\
\hline & Gatenga & 2 & 5.64 & 1 & Low basic-ICT \\
\hline & Gikondo & 4 & 14.69 & 1.15 & High basic-ICT \\
\hline & Kagarama & 4 & 16.37 & 1.14 & High basic-ICT \\
\hline & Kanombe & 4 & 12.82 & 1.11 & High basic-ICT \\
\hline & Kicukiro & 4 & 10.41 & 1.15 & High basic-ICT \\
\hline & Kigarama & 2 & 8.84 & 1.07 & Low basic-ICT \\
\hline & Masaka & 1 & 16.45 & 0.86 & High basic-ICT \\
\hline & Niboye & 4 & 18.14 & 1.23 & High basic-ICT \\
\hline & Nyarugunga & 4 & 7.13 & 1.17 & High basic-ICT \\
\hline \multirow[t]{4}{*}{ Nyarugenge } & Gitega & 2 & 19.88 & 0.99 & Low basic-ICT \\
\hline & Kanyinya & 3 & 9.37 & 0.78 & Low non-basic ICT \\
\hline & Kigali & 3 & 15.58 & 0.81 & Low non-basic ICT \\
\hline & Kimisagara & 2 & 17.16 & 1 & Low basic-ICT \\
\hline
\end{tabular}


Table 8 continued

\begin{tabular}{|c|c|c|c|c|c|}
\hline \multirow[t]{6}{*}{ District } & $\begin{array}{l}\text { Sector } \\
\text { Mageragere }\end{array}$ & $\begin{array}{l}\text { Cluster } \\
3\end{array}$ & $\begin{array}{l}\text { Distance to cluster centre } \\
22.09\end{array}$ & $\begin{array}{l}\text { LQICTagg } \\
0.71\end{array}$ & $\begin{array}{l}\text { Status (cluster type) } \\
\text { Low non-basic ICT }\end{array}$ \\
\hline & Muhima & 4 & 9.91 & 1.11 & High basic-ICT \\
\hline & Nyakabanda & 2 & 11.65 & 1.07 & Low basic-ICT \\
\hline & Nyamirambo & 2 & 7.20 & 1.05 & Low basic-ICT \\
\hline & Nyarugenge & 4 & 10.69 & 1.08 & High basic-ICT \\
\hline & Rwezamenyo & 4 & 24.90 & 1.14 & High basic-ICT \\
\hline
\end{tabular}

Distance to cluster is a dimensionless measure of the typicality of a given sector (area) in the cluster to which it belongs. A smaller measure means closer resemblance or embodiment of the character of the given cluster type

Clarifications and notes on data

Location Quotient (LQ) as applied in this study is explained below:

Location Quotient $(L Q)=\frac{(x / X) \times 100 \%}{(y / Y) \times 100 \%}$

where $x$ is the number of households who own or use the ICT asset/Internet by location relevant to focus digital indicator in a given administrative sector; $\mathrm{X}$ is the total of households in the given administrative sector; $y$ is the number of households who own or use the ICT asset or Internet by location relevant to the focus digital indicator in the reference city(Kigali); Y is the total of households in the reference city(Kigali).

The composite measure of ICT concentration, Location Quotient Aggregate (LQICTagg) is the ratio of the sum of percentage scores for all indicators in the given sector to the sum of percentage scores for all indicators at the reference city level (Kigali). For the purpose of context illustration: unique in terms of the focus indicator or all indicators in the case of LQICTagg. Such sectors have higher concentrations of ICT asset and/or use by location. Sectors with ICTLQ or LQICTagg less than 1 are low concentrations and less specialised.

\section{ICT/digital indicators}

All ICT KPIs used are based on data percentage of households whose at least one member has the referent indicator; physical access indicators are ICT assets/ devices (television, radio, fixed/land phone, mobile phone, computer). In the dimension of use by location, the fundamental indicators are applied; percentage of households whose at least one member has access to Internet by location (home, school/office, cyber café and other places). Other places may not constitute a significant and regular household access outlet. For example using other people's phones sometimes may not constitute a regular access location. Computer may be desktop, laptop, tablet or similar handheld computer.

ICTLQagg of sector $\mathrm{A}=\frac{(\% \text { Radio }+\% \mathrm{TV}+\% \text { Fixed phone }+\% \text { Internet Home } \ldots+\% \text { others }) \text { for sector A }}{(\% \text { Radio }+\% \mathrm{TV}+\% \text { Fixed phone }+\% \text { Internet Home } \ldots+\% \text { others }) \text { for the city }}$

Hence location quotient compares the local share of the focus ICT indicator to that of the reference region, Kigali City. Where ICTLQ (for individual indicator) or LQICTagg (for the composite ICT measure) equals 1 , it indicates that the sector ICT cluster or share is the same as the city share. An ICTLQ or LQICTagg greater than 1 indicates that the sector is specialised or
Internet access is irrespective of the device used; digital TV, tablet, mobile, computer and game machines). Access window is defined normally as 3 months. Online inactivity more than 3 months is defined as no access to Internet. 
Spatial and socio-economic variables

Youth employment: Youth is defined in Rwanda as the population aged 14-35. But working age is 16-64. The youth employed fall within age range 16 and 35 . This is not household-based but individual residents in this group aggregated at sector levels. Employment is any productive, legal engagement, in the last 7 days preceding the census. Those who are not engaged are in the last 7 days are considered temporarily inactive. The percentage of the youth employed or in a particular type of employment (employee/employer/self-employed) is used in this study. The elderly belong to the age group 60 and above.

Youth indicator was deliberately applied as the group plays a role in the digital use environment. This enables the examination of the possible co-existence of youth factor and ICT access. Taking the other extreme of youth (the elderly) makes for a clear comparison as those should naturally unveil any agedivide in digital access. However, any possible lopsidedness is evened out since the actual ICT KPIs used are based on cross-cutting age groups in households (irrespective of age). The extreme groups were applied only as socio-economic correlates for relationship test, not ICT KPIs.

Secondary school age is $13-18$ in Rwanda. The percentage of the population within this group who have attained secondary school (as highest level of education) was used. For university as highest level of education, the share of youth population who attained university education was used.

Post primary education centre is any formal school above primary school; this includes formal vocational institutes where certificates are awarded, recognised by GoR. In this study it is the number of such centres in a given sector. It was used as surrogate for possible innovation centres.

Share of total population is a given sector's population expressed as percentage of its host district. This makes it useful for local context. Comparison is applicable since it has been regularised as a percentage. Note that these computations were the official statistics. Where the author computes figures these are clearly stated; for example Location Quotients.

Those variables that typically tend to have spatial footprint and distinguish the core from the periphery have been conceived in this context to be spatial. Some variables have elements of social and economic constructs (socio-economic); for example female household heads who are typically the providers of the household needs; status which could as well limit access to resources where gender is a strong factor. Education as used here is primarily a social indicator relevant for understanding, partly, the digital natives, awareness and general literacy. There is no hard and fast rule for this kind of categorisation and none is being set in this study. Nomenclature has only been applied for the purpose of contextual understanding of the underlying condition of ICT access in Kigali City.

Percentage planned is given in the official data and based on proportion of households in the type of habitat (in sectors) considered to meet the planning standard required to be classified as planned, spontaneous or others.

Urban population is defined as urban percentage of the total population. It is on the basis of settlement type and other elements considered as dominantly urban in the given sector. It is individual resident-based, not household. Since the data was used mainly as a spatial-statistical indicator, not directly collected from urban planning authorities, this is expected to be generalised and sufficient for the purpose of analysis; where the study is not particularly one of land use or settlement analysis.

Home ownership considers household tenure. It is the percentage of households who live in their own homes. This is a (social) indicator of tenure security. "Owner" may include inheritance, not necessarily self-financed but distinguishable from tenant, free lodging, hire purchase or staff housing. Hence, quality or formality plays less role in this case; an urban fringe household in own apartment without the modern facilities and furnishing, which may be available in a well-manicured home at the core, is considered an owner and enjoys the security thereof.

Electricity is a subset of household sources of energy for lighting, with others being candle, firewood and kerosene lamps mainly used in the remote/rural areas, which are most affected by power outage or in some cases not connected to the national grid. It is the percentage of households who use electricity as the primary source of lighting.

Improved water source is aggregated from households and simply classified as either improved or unimproved, taking into account local quality standards not specified in the statistical data. As used in the 
study, it is the percentage of households who have access to improved water source.

Geographic constraint is the proportion/percentage of a given sector that is unfavourable for development purposes. Geographic constraint refers to limitations associated with land: unfavourable steepness/topography, soils, wetlands and forests ill-suited for new development based on scientific and ecological principles (City of Kigali 2013). Hence, a sector's share of these physical-ecological ills may be indicative of relative backwardness, which could as well be a correlate of performance in emergent technology availability and use. For example difficulty in laying fibre optic, base transceiver stations or poor signal due to geographic constraints could reflect in poor ICT ownership and use in the affected sector.

\section{References}

Baller, S., Dutta, S., \& Lanvin, B. (2016). Global information technology report 2016. Geneva: Ouranos.

Barzilai-Nahon, K. (2006). Gaps and bits: Conceptualising measurements for digital divides. The Information Society, 22(5), 269-278. https://doi.org/10.1080/019722406009 03953.

Basu, P., \& Chakraborty, J. (2011). New technologies, old divides: Linking internet access to social and locational characteristics of US farms. GeoJournal, 76(5), 469-481. https://doi.org/10.1007/s10708-010-9370-x.

Baum, S., Gellecum, Y. Van, \& Yigitcanlar, T. (2004). Wired communities in the City: Sydney, Australia. Australian Geographical Studies, 42(2), 175-192. https://doi.org/10. 1111/j.1467-8470.2004.00274.x.

Berhe, R. T., Martinez, J., \& Verplanke, J. (2014). Adaptation and dissonance in quality of life: A case study in Mekelle, Ethiopia. Social Indicators Research, 118(2), 535-554. https://doi.org/10.1007/s11205-013-0448-y.

Burger, M., van Oort, F., \& van der Knaap, B. (2008). A treatise on the geographical scale of agglomeration externalities and the modifiable areal unit problem (No. ERS-2008-076ORG). Available at: https://repub.eur.nl/pub/13834/.

Buys, P., Dasgupta, S., Thomas, T. S., \& Wheeler, D. (2009). Determinants of a digital divide in Sub-Saharan Africa: A spatial econometric analysis of cell Phone coverage. World Development, 37(9), 1494-1505. https://doi.org/10.1016/j. worlddev.2009.01.011.

City of Kigali. (2013). Detailed district physical plans for Kicukiro and Gasabo, Kigali Rwanda: Kigali City; analysis, benchmarking \& vision report. Kigal: CoK.

Crang, M., Crosbie, T., \& Graham, S. (2006). Variable geometries of connection: Urban digital divides and the uses of information technology. Urban Studies, 43(13), 2551-2570.
Dewan, S., \& Riggins, F. J. (2005). The digital divide: Current and future research directions. Journal of the Association for Information Systems, 6(12), 298-337.

De Winter, J. C. F., Dodou, D., \& Wieringa, P. A. (2009). Exploratory factor analysis with small sample sizes. Multivariate Behavioral Research, 44(2), 147-181. https://doi. org/10.1080/00273170902794206.

Dodel, M. (2015). An analytical framework to incorporate ICT as an independent variable. In A. Chib, et al. (Eds.), Impact of information society research in the global south (pp. 125-144). Singapore: Springer. https://doi.org/10.1007/ 978-981-287-381-1.

Eynon, R., \& Helsper, E. (2014). Family dynamics and internet use in Britain: What role do children play in adults' engagement with the internet? Information, Communication \& Society, 4462(2015), 1-16. https://doi.org/10.1080/ 1369118X.2014.942344.

Fuchs, C., \& Horak, E. (2008). Africa and the digital divide. Telematics and Informatics, 25(2), 99-116. https://doi.org/ 10.1016/j.tele.2006.06.004.

Graham, M. (2011). Time machines and virtual portals: The spatialities of the digital divide. Progress in Development Studies, 11(3), 211-227. https://doi.org/10.1177/ 146499341001100303.

Graham, M. (2015). Information geographies and geographies of information. In A. Fard \& T. Meshkani (Eds.), New geographies 07: Geographies of information (pp. 159-166). Cambridge: Havard University Press.

Graham, M., Hale, S., \& Stephens, M. (2012). Featured graphic: Digital divide: The geography of internet access. Environment and Planning A, 44(5), 1009-1010. https://doi. org/10.1068/a44497.

Graham, S., \& Marvin, S. (2001). Splintering urbanism: Networked infrastructures, technological mobilities and the urban condition (1st ed.). London: Routledge.

Grant, U. (2012). Education for all global monitoring report: Youth and skills: Putting education to work; Urbanisation and the employment opportunities of youth in developing countries. Paris: UNESCO. Retrieved from http://www. unesco.org/ulis/cgi-bin/ulis.pl?catno $=217879 \&$ set $=$ 00550F1190_1_349\&gp=0\&lin=1\&11=1.

Hanafizadeh, M. R., Hanafizadeh, P., \& Bohlin, E. (2013). Digital divide and e-readiness. International Journal of E-Adoption, 5(3), 30-75. https://doi.org/10.4018/ijea. 2013070103.

Heeks, R., \& Ospina, A. V. (2018). Conceptualising the link between information systems and resilience: A developing country field study. Information Systems Journal. https:// doi.org/10.1111/isj.12177.

Hove, M., Ngwerume, E. T., \& Muchemwa, C. (2013). The urban crisis in Sub-Saharan Africa: A threat to human security and sustainable development. Stability, 2(1), 1-14. https://doi.org/10.5334/sta.ap.

International Telecommunication Union/ITU. (2014). Manual for measuring ICT access and use by households and individuals. Geneva: ITU.

International Telecommunication Union/ITU. (2016). Key areas of action. Retrieved July 14, 2016, from https://www.itu. int/en/action/Pages/default.aspx. 
International Telecommunication Union/ ITU. (2017). ICT development Index 2017. http://www.itu.int/net4/ITU-D/ idi/2017/. Accessed 17 May 2018.

ITU/UNESCO. (2017). The State of Broadband 2017. Geneva: ITU. Available at: https://www.itu.int/pub/S-POLBROADBAND. 18.

Jaglin, S. (2008). Differentiating networked services in Cape Town: Echoes of splintering urbanism? Geoforum, 39(6), 1897-1906. https://doi.org/10.1016/j.geoforum.2008.04. 010.

Juris, J. S. (2012). Digitality and socio-political networks. In G. Ritzer (Ed.), Encyclopedia of globalization (pp. 438-441). Hoboken, New Jersey: Blackwell.

Kelley, M. J. (2014). Urban experience takes an informational turn: Mobile internet usage and the unevenness of geosocial activity. GeoJournal, 79(1), 15-29. https://doi.org/10. 1007/s10708-013-9482-1.

Li, Y., \& Ranieri, M. (2013). Educational and social correlates of the digital divide for rural and urban children: a study on primary school students in a provincial city of China. Computers \& Education, 60(1), 197-209. https://doi.org/ 10.1016/j.compedu.2012.08.001.

Loader, B. (Ed.). (1998). Cyberspace Divide. Equality, Agency and Policy in the Information Society. London: Routledge.

Makela, T. (2001). Re-reading digitality through scientific discourses of cybernetics: fantasies of disembodied users and embodied computers. In A. Koivunen \& S. Paasonen (Eds.), Conference proceedings for affective encounters: Rethinking embodiment in feminist media studies. Turku: University of Turku.

Martin, R. (2012). Regional economic resilience, hysteresis and recessionary shocks. Journal of Economic Geography, 12(1), 1-32. https://doi.org/10.1093/jeg/lbr019.

Myrdal, G. (1957). Economic theory and underdeveloped regions. London: Duckworth.

National Institute of Statistics of Rwanda/NISR. (2015). District profiles: Kicukiro, Nyarugenge and Gasabo. Kigali: NISR.

Negroponte, N. (1995). Being digital (1st ed.). New York: Vintage Books.

Noce, A. A., \& McKeown, L. (2008). A new benchmark for internet use: A logistic modeling of factors influencing Internet use in Canada, 2005. Government Information Quarterly, 25(3), 462-476. https://doi.org/10.1016/j.giq. 2007.04.006.

Ogutu, S. O., Okello, J. J., \& Otieno, D. J. (2014). Impact of information and communication technology-based market information services on smallholder farm input use and productivity: The case of Kenya. World Development, 64(104482), 311-321. https://doi.org/10.1016/j.worlddev. 2014.06.011.

Pacione, M. (2001). Urban geography: A global perspective (2nd ed.). New York: Routledge.

Pick, J. B., \& Nishida, T. (2015). Digital divides in the world and its regions: A spatial and multivariate analysis of technological utilization. Technological Forecasting and Social Change, 91, 1-17. https://doi.org/10.1016/j.techfore.2013. 12.026 .

Pick, J. B., Nishida, T., \& Zhang, X. (2013). Determinants of China's technology availability and utilization 2006-2009: A spatial analysis. The Information Society, 29(1), 2013.
Pick, J. B., Sarkar, A., \& Johnson, J. (2015). United States digital divide: State level analysis of spatial clustering and multivariate determinants of ICT utilization. Socio-Economic Planning Sciences, 49, 16-32. https://doi.org/10. 1016/j.seps.2014.09.001.

Prensky, M. (2001). Digital natives, digital immigrants. On the Horizon, 9(5), 1-6. https://doi.org/10.1108/ 10748120110424816.

Riddlesden, D., \& Singleton, A. D. (2014). Broadband speed equity: A new digital divide? Applied Geography, 52, 25-33. https://doi.org/10.1016/j.apgeog.2014.04.008.

Robin, L., Villasenor, J. D., \& West, D. M. (2017). The 2017 Brookings financial and digital inclusion project: Building a Secure and Inclusive Global Financial Ecosystem. Washington DC: Centre for Technology Innovation at Brookings.

Rogerson, P. (2015). Statistical methods for geography: A student's guide (4th ed.). Los Angeles: Sage.

RURA. (2013). Strategic Plan 2013-2018. Retrieved from https://www.uow.edu.au/content/groups/public/@web/ @ spq/documents/doc/uow135458.pdf.

RURA. (2016). Universal Access Fund and broadband penetration. Retrieved June 1, 2016, from http://www.rura.rw/ index.php?id=143.

Scott, K. (2015). The "digital city": A critical examination of the discursive practices of urban digitality in three U.S. Cities, George Mason University, Fairfax, VA.

Selwyn, N. (2004). Reconsidering political and popular understandings of the digital divide. New Media and Society, 6(3), 341-362. https://doi.org/10.1177/14614448040 42519.

Smit, M. J., Abreu, M. A., \& de Groot, H. L. F. (2013). Microevidence on the determinants of innovation in the Netherlands: The relative importance of absorptive capacity and agglomeration externalities. Papers in Regional Science, 94(2), 250-272. https://doi.org/10.1111/pirs.12068.

Soja, E. W. (2009). The city and spatial justice. Justice Spatiale Spatial Justice, 1, 1-5. Available at: https://www.jssj.org/ wp-content/uploads/2012/12/JSSJ1-1en4.pdf.

Song, W. (2008). Development of the Internet and digital divide in China: A spatial analysis. Intercultural Communication Studies, 12(3), 20-43.

Steenbruggen, J., Borzacchiello, M. T., Nijkamp, P., \& Scholten, H. (2013). Mobile phone data from GSM networks for traffic parameter and urban spatial pattern assessment: A review of applications and opportunities. GeoJournal, 78(2), 223-243. https://doi.org/10.1007/s10708-011-9413-y.

Terlouw, K., \& Denkers, R. (2011). The geography of regional websites: Regional representation and regional structure. Geoforum, 42(5), 578-591. https://doi.org/10.1016/j. geoforum.2011.05.003.

The Economist.(2017). The Inclusive Internet Index. The Economist: Intelligence Unit. Retrieved from: https:// theinclusiveinternet.eiu.com/.

Thompson, S. J. (2010). Iconics: icon evolution in digitality. TripleC, 8(2), 351-360.

Tranos, E., Kourtit, K., \& Nijkamp, P. (2013). Mobile phone data and urban analysis: An exploratory space-time study. Tinbergen Discussion Paper, 139(8), 1-14.

Tranos, E., Kourtit, K., \& Nijkamp, P. (2014). Digital urban network connectivity: Global and Chinese internet 
patterns. Papers in Regional Science, 93(2), 409-428. https://doi.org/10.1111/pirs.12097.

UNDP. (2015). Human Development Report 2015: Work for Human development. Retrieved from http://hdr.undp.org/ sites/all/themes/hdr_theme/country-notes/MEX.pdf.

UN-Habitat. (2015). The role of ICT in the proposed Urban sustainable development goals and the new urban agenda. Nairobi: UN-Habitat. Retrieved from http://www.ericsson. $\mathrm{com} / \mathrm{kn} / \mathrm{res} / \mathrm{docs} / 2014 /$ the-role-of-ict-in-the-new-urbanagenda.pdf.

US Bureau of Labour Statistics. (2011). Occupational Employment Statistics (OES) highlights: Using Location quotients to analyze occupational data, (April). Retrieved from http://www.bls.gov/oes/highlight_location_quotients. pdf.

Van Deursen, A., Courtois, C., \& van Dijk, J. (2014). Internet skills, sources of support, and benefiting from internet use. International Journal of Human-Computer Interaction, 30(4), 278-290. https://doi.org/10.1080/10447318.2013. 858458 .

Van Deursen, A. J. A. M., \& Helsper, E. J. (2015). The thirdlevel digital divide: Who benefits most from being online? In L. Robinson, S. R. Cotten, J. Schulz, T. M. Hale, \& A. Williams (Eds.), Communication and information technologies annual (Vol. 10, pp. 29-52). Emerald Group Publishing Limited.

Van Dijk, J. (2005). The deepening divide inequality in the information society. London: Sage Publications.

Várallyai, L., Herdon, M., \& Botos, S. (2015). Statistical analyses of digital divide factors. Procedia Economics and Finance, 19(15), 364-372. https://doi.org/10.1016/S22125671(15)00037-4.

Vicente, M. R., \& López, A. J. (2011). Assessing the regional digital divide across the European Union-27. Telecommunications Policy, 35(3), 220-237. https://doi.org/10.1016/j. telpol.2010.12.013.

Whitacre, B. E. (2008). Factors influencing the temporal diffusion of broadband adoption: evidence from Oklahoma. Annals of Regional Science, 42(3), 661-679. https://doi. org/10.1007/s00168-007-0178-7.

World Economic Forum/INSEAD. (2016). The Global Information Technology Report 2016. In S. Baller, S. Doutra, \& B. Lavin, (Eds.) Geneva: World Economic Forum/ INSEAD.

Zook, M. A. (2001). Old hirearchies or new networks of centrality? The global geography of Internet content market. American Behavioural Scientist, 44(10), 1679-1696. 